\title{
Childhood mortality in Mosul city during the year 2007
}

\author{
Amaema A. Al-Zubeer \\ Department of Community Medicine, College of Medicine, University of Mosul.
}

(Ann. Coll. Med. Mosul 2009; 35(1): 1-7).

Received: $20^{\text {th }}$ May 2008; Accepted: $24^{\text {th }}$ Sept 2008.

\begin{abstract}
Objectives: To calculate infant and under five mortality rates and to find out the most common causes of death among children.
\end{abstract}

Methods:

Study period: The study was done over a period of one month, during Dec. 2007.

Study design: Rapid epidemiological survey using UNICEF "last birth technique".

Study setting: The study was done at Al-Hadbaa Primary Health Care Center in Mosul city.

Study population: Data was collected from 1046 mothers in child bearing age (15-49 years), who were attending at the antenatal clinic by direct interviewing using a questionnaire form based on the model formulated by UNICIF for childhood mortality survey.

Results: The present study showed that the estimated under five mortality rate is 107 /1000 of last live births which represents a rise of 2.5 fold since WHO Maternal and Child Mortality Survey was done at 1990 in Iraq. The Infant mortality rate was estimated to be 95.6 death / 1000 of last live births. The study also showed that the neonatal mortality (0-28 days) constitutes $40.9 / 1000$ last live birth which accounts for $42 \%$ from all deaths that occur during $1^{\text {st }}$ year of life. Other findings showed that more than a quarter of all causes of deaths among under five were related to respiratory problems and $15.5 \%$ of all causes were linked to congenital abnormalities. Diarrheal disease accounted for $8.6 \%$ of causes.

Conclusion: Results showed that under five mortality is still considered a major health problem and reflecting defect in health system of the community, needs to be re-evaluated and minimized to be as least as possible.

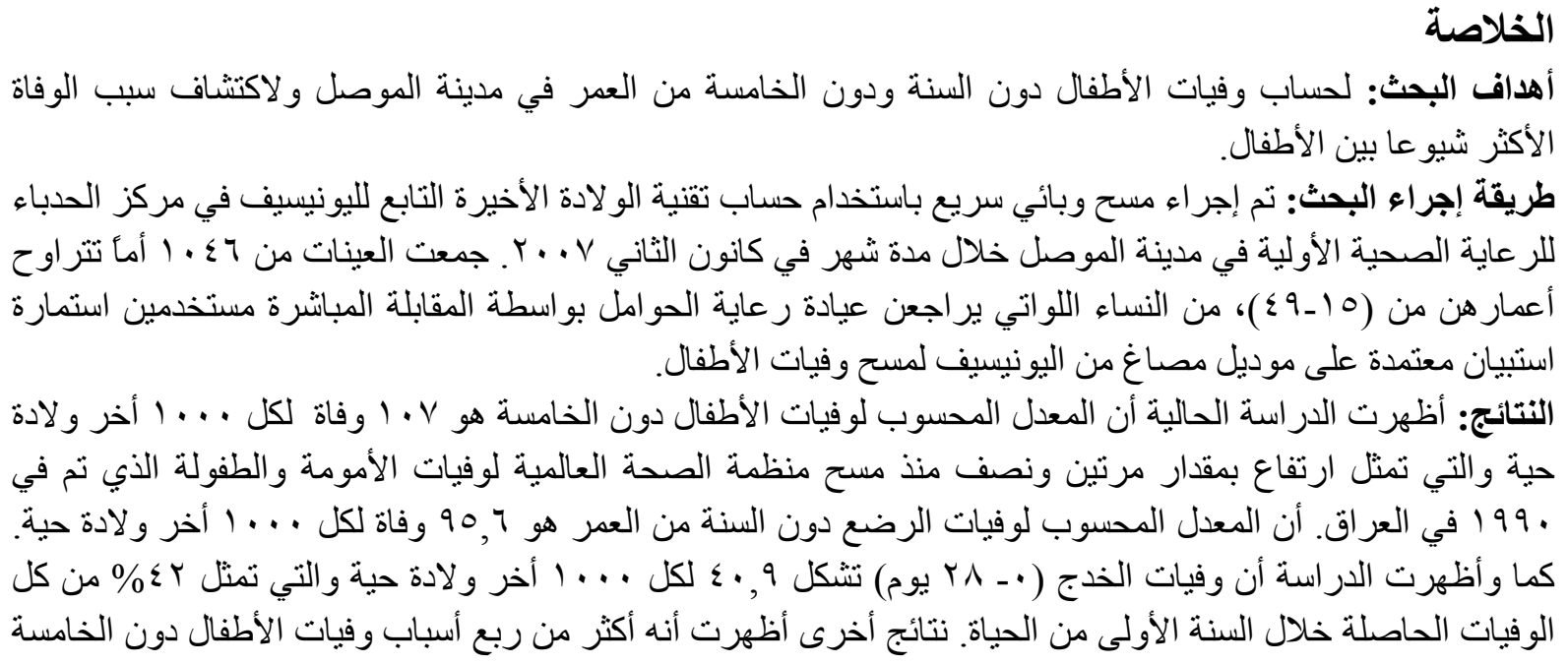




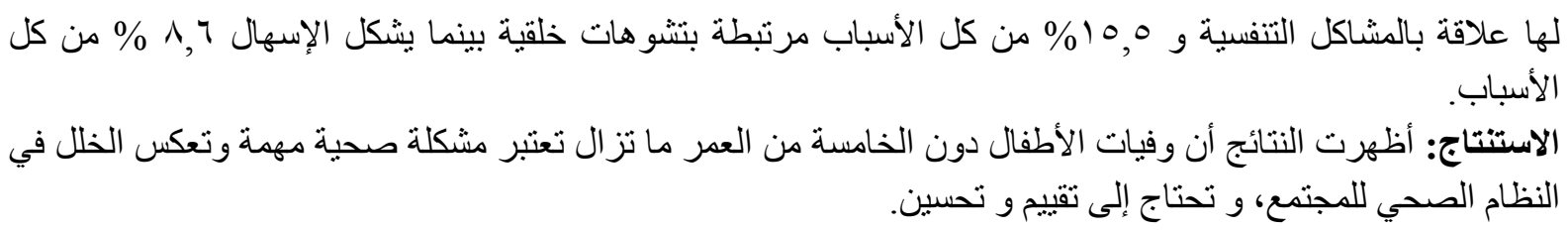

C hildren are the future of society and their mothers are guardians of that future ${ }^{(1)}$. Pregnancy, child birth and their consequences are still the leading causes of death, disease and disability among women of reproductive age in developing countries ${ }^{(2)}$. Childhood mortality which comprises infant mortality rate and under five mortality rate are key indicators used internationally, nationally and locally as a sensitive but not specific way of comparing health status and development within countries ${ }^{(3)}$. Under five mortality rate is also a good reflection of the general wellbeing of children in an area ${ }^{(4,5)}$. Across the world there is an overall downward trend in under five mortality rates ${ }^{(6,7)}$. However, this trend was showing sign of slowing lately, though till the year 2005, almost 11 million children under five years of age died from causes that are largely preventable globally. Among them are 4 million who will not survive the first month of life ${ }^{(1,8)}$. Poor or delayed care-seeking contributes up to $70 \%$ of child death. More than $50 \%$ of all child deaths globally occur in just six counties: China, the Democratic Republic of Congo, Ethiopia, India and Pakistan ${ }^{(8)}$. There are several factors contributing to the death of infants and children ${ }^{(9)}$, these include socio-demographic status of family, level of community development and education, (availability, access and quality of health services) with neonatal mortality is associated with maternal health and access to care around the time of delivery and the presence of preventive and curative health services ${ }^{(10,11)}$ which in fact are still poor in Iraq.

The aim of the present study is to determine the under five mortality in the catchment area of Al- Hadbaa Primary Health Care Center in Mosul city during the year 2007 using rapid epidemiological survey and to find out the most common causes of death among the study sample.

\section{Specific objective}

To estimate the under five mortality rate, infant mortality rate and neonatal mortality among the study sample.

To find out the most common causes of death among children under five years of age.

To compare the estimated present under five mortality rates with previous rates that have been estimated in Iraq.

\section{Methods}

The survey was conducted at Al-Hadbaa Primary Health Care Center which represents one of the most crowded centers in Mosul city. The study sample included 1046 mothers in child bearing age (15-49 years) who attended at the antenatal clinic in the center which represent $87 \%$ of all mothers attending the center during one month period. This center has a catchment area of approximately 13000 women in child bearing age and 11500 children under five years ${ }^{(12)}$. The study was conducted during Dec. 2007. A questionnaire form was prepared using "last birth technique" module formulated by UNICEF for childhood mortality survey in developing countries ${ }^{(11)}$. The questionnaire included information about mother's age, previous deliveries and the outcome of each delivery, causes of death if present and age of child at death. It was reviewed with teaching staff of community department to assess its validity which was $92 \%$. Results approach was applied on it to measure the reliability of the answers, and it was correct in $81 \%$. Filling up the questionnaire form was done by direct interview with the mothers at the antenatal clinic. The response rate was $97 \%$. In addition to that, the investigator had visited the Statistical Unit in Nineveh Health Office and Al-Khannsa Hospital and the under five mortality rates were calculated from the registered deaths in the records of those units for comparison purposes. 
Age specific parity was calculated by dividing the number of children ever born in a specific age group over the total number of mothers in that age group. The under five mortality rates were calculated by dividing the total number of children died below five years over the total number of last live birth multiplied by one thousand. Similar procedure was done to calculate the infant and neonatal mortality rates ${ }^{(13,14)}$.

Data collection, computer feeding, tabulation and statistical analysis were conducted by the investigator herself using Minitab statistical software version XIII. Chi square test was used and odds ratio for finding association.

\section{Results}

Table (1) shows that the overall estimated under five mortality rate is $107 / 1000$ live births. From the analysis of data of the present study, the estimated infant mortality rate is 95.6 deaths $/ 1000$ last live birth. Neonatal mortality ( $0-28$ days) constitutes $40.9 / 1000$ last live birth which account for $42 \%$ of all deaths that occur during $1^{\text {st }}$ year of life. The table also indicates that less than five mortality is higher among age group (45-49), as it reaches 208.5 per 1000 live births.

Table (2) represents the estimation of risk of under five deaths among women age 45-49 years in comparison with the other age groups. Children whose mothers' age among the age range 45-49 year have significantly 2 fold risk of under five death than other children $(\mathrm{OR}=2.2,95 \% \mathrm{Cl}=(1.510,2.917), \mathrm{P}$ value $<0.001)$.

Table (3) shows that the average parity per mother is increased with increasing mother's age as an average of one child / mother in the age group 15-20 years to reach six children Imother in the age group 45-49.

Table (4) exhibits that respiratory problems constitute about $26.3 \%$ and congenital abnormalities form $15.5 \%$ from all causes of death. Fever was encountered in $13.6 \%$. Other causes include injury, accidents, meningitis and septicemia which make a fraction of $18.3 \%$ from the causes. In addition to that male deaths exceeded female deaths among all causes.

Table (1): Under five mortality according to age of mothers using last birth technique in Mosul 2007

\begin{tabular}{|c|c|c|c|}
\hline $\begin{array}{l}\text { Mother's age } \\
\text { group }\end{array}$ & No. of live birth & $\begin{array}{l}\text { No. of deaths of } \\
\text { children }\end{array}$ & $\begin{array}{l}\text { Under five mortality rate/1000 live } \\
\text { birth }\end{array}$ \\
\hline 15- & $\overline{56}$ & $\overline{c \ldots \ldots}$ & $\overline{c \ldots \ldots}$ \\
\hline $20-$ & 586 & 18 & 30.7 \\
\hline 25- & 516 & 82 & 158.9 \\
\hline $30-$ & 512 & 24 & 46.87 \\
\hline $35-$ & 824 & 80 & 97.08 \\
\hline $40-$ & 637 & 107 & 167.97 \\
\hline $45-49$ & 235 & 49 & 208.5 \\
\hline Total & 3366 & 360 & $107 / 1000$ \\
\hline
\end{tabular}

Table (2): Risk of under five mortality among women age 45-49 in the study sample

\begin{tabular}{|l|c|c|c|}
\hline & Deaths & Live births & Total \\
\hline \hline Age group (45-49) & 49 & 235 & 284 \\
\hline Other age group & 311 & 3131 & 3442 \\
\hline Total & 360 & 3366 & 3726 \\
\hline
\end{tabular}

$(\mathrm{P}<0.001, \mathrm{OR}=2.2,95 \% \mathrm{Cl}=1.510-2.917)$. 
Table (3): Age distribution of women with their total children ever born and average parity

\begin{tabular}{|l|c|c|c|c|c||}
\hline \multirow{2}{*}{ Mother's age group } & \multirow{2}{*}{ All women } & \multicolumn{3}{c|}{ No. of children ever born } & \multirow{2}{*}{$\begin{array}{c}\text { Average } \\
\text { parity } \\
\text { /mother }\end{array}$} \\
\cline { 3 - 5 } & & Male & Female & Total & 1.16 \\
\hline \hline $15-$ & 48 & 32 & 24 & 56 & 2.02 \\
\hline $20-$ & 298 & 315 & 289 & 604 & 2.62 \\
\hline $25-$ & 228 & 279 & 319 & 598 & 3.82 \\
\hline $30-$ & 140 & 255 & 281 & 536 & 5.13 \\
\hline $35-$ & 176 & 469 & 435 & 904 & 6.58 \\
\hline $40-$ & 113 & 389 & 355 & 744 & 6.60 \\
\hline $45-49$ & 43 & 166 & 118 & 284 & Sum \\
\hline Total & 1046 & 1905 & 1821 & 3726 & \\
\hline
\end{tabular}

Table (4): Distribution of death cases by causes and sex

\begin{tabular}{||l|c|c|c|c||}
\hline \multicolumn{1}{|c|}{ Causes } & Male & Female & Total & Percent \\
\hline \hline Respiratory* problem & 59 & 36 & 95 & 26.38 \\
\hline Congenital abnormality & 27 & 29 & 56 & 15.55 \\
\hline Fever & 22 & 27 & 49 & 13.6 \\
\hline Premature & 15 & 18 & 33 & 9.1 \\
\hline Diarrhea $^{\star}$ & 15 & 16 & 31 & 8.6 \\
\hline Unknown $^{\star}$ & 18 & 12 & 30 & 8.3 \\
\hline Others & 36 & 30 & 66 & 18.3 \\
\hline Totals & 192 & 168 & 360 & $100 \%$ \\
\hline
\end{tabular}

$*$ These causes are classified under international classification of diseases $10^{\text {th }}$ revision ${ }^{(15,16,17)}$. ${ }^{* \star}$ Others: Include injury, accidents, meningitis, septicemia.

\section{Discussion}

Childhood mortality rates are used to determine the level of human and economic development of the country ${ }^{(18,19)}$. The present survey indicates that under five mortality rates is $107 / 1000$ last live birth which represents 2.5 fold rise of under five mortality rates estimated by UNICIF/WHO maternal and child mortality survey done at 1990 which was 41/1000 live birth ${ }^{(20,21)}$. The results that were obtained from the vital registration system show that the estimated under five mortality for the year 2007 is $24 / 1000$ live birth and the infant mortality rate is $19.5 / 1000$ live birth that occur during the year 2007. Another datum that has been taken from the Statistics Unit of AlKhannsa Hospital shows more or less similar results as under five mortality rate was $32 / 1000$ live birth and the IMR was $28.58 / 1000$ live birth. These findings yield that only $20.4 \%$ of all infant mortality which occurred has been registered and only $22.4 \%$ of real under five mortality has been registered as compared with the present survey results ${ }^{(22)}$. Similarly, almost one third of deaths $(29.8 \%)$ has been registered in Al-Khannsa Hospital Statistical Unit for both infant and under five mortality when compared with the result of the present survey ${ }^{(23)}$. This is due to information on deaths from the health information system, unfortunately, does not reflect the mortality picture from population perspective because it is government facility - based data and thus does not include deaths that occur outside such facilities or from private heath institutions (24). In many developing countries, vital registration data are incomplete. The severity of the under-reporting varies from country to country, and also varies over time within 
countries ${ }^{(25)}$. This under reporting of the registration system represents the top of the iceberg phenomena ${ }^{(14)}$. Birth history information from surveys provides the most robust estimation of infant and child mortality $(12,26)$

A survey done at rural area near Mosul during 1992 showed rise in under five mortality rates of 61 death $/ 1000$ live birth ${ }^{(28)}$. Another survey done at Al-Zangelle district in Mosul city during the year 2002 showed that under five mortality rates was $166 / 1000$ live birth ${ }^{(29)}$. The present study picture may reflect slight decline in childhood mortality since 2002 but it is still very high and unless progress is accelerated significantly, there is little hope of reducing child mortality by two thirds by the target date of 2015 - the targets set by the millennium declaration ${ }^{(8)}$. Globally there is decline in the child mortality as mentioned by WHO ${ }^{(8)}$, while, the actual number of deaths is highest in Asia ${ }^{(30,31)}$, the rates for both neonatal deaths and still births are greatest in Sub Sahara Africa ${ }^{(27)}$. In addition to that, it was reported that there are some regions of the world which underwent humanitarian crisis where mortality rates are "stagnating" and Iraq is one of these regions ${ }^{(8)}$. A study done during 2004 for estimation of mortality before and after 2003 invasion of Iraq showed that the risk of death was estimated to be 2.5 higher after invasion when compared with pre invasion period ${ }^{(32)}$. The present study revealed that there is a steady increase in the average parity per mother with increase of age of mothers. This gives explanation of why mortality rate is still stagnating because modest reductions of mortality rates are too small to keep up with the increasing numbers of births ${ }^{(8)}$.

The present study also showed that the estimated infant mortality rate is $95.5 / 1000$ last live birth and neonatal mortality is $40 /$ 1000 last live birth. Thus the neonatal mortality constitutes $42 \%$ of all deaths that occur during $1^{\text {st }}$ year of life. Across the world, newborn deaths contribute to about $40 \%$ of all deaths in children under five years of age and more than half of infant mortality ${ }^{(8)}$. A survey done by UNICEF at early nineties showed that infant mortality rate was 32 per thousand live births during 1990 and increased afterwards to 93 deaths per thousand live births $1994^{(20)}$.

Another result of the present study indicated that the most common cause of deaths among under five was respiratory problems as they constitute $26.3 \%$ of all causes, these problems occur most commonly within the $1^{\text {st }}$ year of life. Across the world, deaths among under five are still attributable to just handful of conditions that are avoidable through existing interventions ${ }^{(1)}$. These are acute lower respiratory infection mostly pneumonia (10\%) of all death, diarrhea (15\%), measles (4\%), HIVIAIDS (3\%), and neonatal conditions and mainly preterm birth, birth asphyxia and infections $(37 \%)^{\left({ }^{(8)}\right.}$. The present study also revealed that mortality among males is higher than females; this could be due to boys being more frail than girls. Many studies had confirmed this trend in mortality ${ }^{(19,24)}$.

\section{Conclusions and recommendations}

There is high rate of childhood mortality recognized in Mosul city during the year 2007 together with the presence of high fertility rate and so there is an urgent need for strategy for prevention of childhood mortality in Iraq through health services provision and socioeconomic development and improvement of family planning facilities.

\section{References}

1. World Health Organization. Monitoring the Situation of Children and Women: Findings from the Multiple Indicator Cluster Survey, UNICEF report, 2006.

2. Rutstein SO. Factors associated with trends in infant and child mortality in developing countries during the 1990s. Bulletin of the World Health Organization 2000; 78: 1256-70.

3. Korenromp EL, Arnold F, Williams BG, Nahlen BL and Snow RW. Monitoring trends in under-5 mortality rates through national birth history surveys. International Journal of Epidemiology 2004; 33: 12931301.

4. Dunkelberg E. Measuring Child Well-Being in the Mediterranean Countries -Toward a Comprehensive Child Welfare. Amsterdam Institute for International 
Development, Wagstaff and Watanabe (2000): p 23.

5. Randall B, Wilson A. The 2006 annual report of the Regional Infant and Child Mortality Review Committee. S D Med 2007; 60(9): 343, 345, 347.

6. Ahmad OB, Lopez AD and Inoue M. The decline in child mortality: a reappraisal. Bulletin of the World Health Organization, 2000, 78 (10): 1175-1191.

7. Khawja M. The extraordinary decline of infant and childhood mortality among Palestinian refugees. Social Science and Medicine 2004; (58): 463-470.

8. World Health Organization. Facts and figures from the World Health Report 2005: Make every mother and child count. 1211 Geneva 27, Switzerland: WHO report; 2007.

9. Etard JF, Hesran J L, Diallo A, Diallo JP, Ndiaye JL and Delaunay V. Childhood mortality and probable causes of death using verbal autopsy in Niakhar. International Journal of Epidemiology 2004; 33: 1286-1292.

10. Wagstaff $A$. Socioeconomic inequalities in child mortality: comparisons across nine developing countries. Bulletin of the World Health Organization 2000; 78(1): 19-29.

11. Shaw C, Blakely $T$, Atkinson $J$ and Crampton P. Do social and economic reforms change socioeconomic inequalities in child mortality? A case study: New Zealand 1981-1999. Journal Epidemiolology Community Health 2005; 59: 638-644.

12. UNICEF MENA. Measuring childhood mortality: A hand book for rapid surveys. The regional office in collaboration with the London school of Hygiene and tropical Medicine; 1988.

13. Haupt A and Kane T. POPULATION HAND BOOK. Fifth Edition. USA: Washington, DC; 2004: 14-17.

14. Gordis L. Epidemiology. $1^{\text {st }}$ edition. USA: W.B. Saunders Company; 1996: 137139.15-National institute for Public Health and the Environment. Revision of the International Classification of Diseases. Newsletter 2007; 5(1): 1-4.
15. National institute for Public Health and the Environment. Revision of the International Classification of Diseases. Newsletter 2007; 5(1): 1-4.

16. Colorado Department of Public Health. New International Classification of Diseases (ICD-10): The History and Impact. Brief health statistic section. Annual report Colorado Vital Statistics, 2001; 41.

On the Web: www.cdphe.state.co.us/hs/.

17. Centers for Disease Control and Prevention. International Classification of Diseases 10th Revision (ICD-10). Department of Health and Human Services. National Center for Health Statistics report; 2001. www.cdc.gov/nchs/about/major/dvs/mortd ata.htm.

18. Collison D, Dey C, Hannah G and Stevenson L. Income Inequality and Child Mortality in Wealthy Nations. Journal Public Health. 2007 ; 29(2): 114-7.

19. Woelk GB, Arrow J, Sanders DM, Loewenson $R$ and Ubomba-Jaswa $P$. Estimating child mortality in Zimbabwe: results of a pilot study using the preceding births technique. Central Africa Journal Medicine. 1993; 39(4): 63-70.

20. UNICEF. Situation Analysis of Children and Women In Iraq. UNICEF/Iraq Report; 1998.

21. Ali M, Blacker J and Jones G. Annual mortality rates and excess deaths of children under five in Iraq, 1991-98. World Health Organization, London School of Hygiene and Tropical Medicine, UNICEF report ; 2003.

22. Vital Statistic Unit. Nineveh Health Office; 2007.

23. Vital Statistic Unit. Al-Khannsa teaching hospital ;2007.

24. Noymer A. Estimates of Under-five Mortality in Botswana and Namibia: Levels and Trends. The Botswana DHS: Family Heath Survey; 1998.

25. Omariba W. Changing childhood mortality conditions in Kenya: An examination of levels, rends and Determinants in the late 1980 s and the 1990s. Population studies 
Centre: University of Western Ontario. London, Canada; 1998.

26. Singh Kerosene, Karunakra U, Burnham G and Hill k. Using Indirect Methods to understand the impact of forced Migration on long -term under-five mortality. Cambridge University Press 2004; 00: 120.

27. Bradshaw D and Dorrington R. Child mortality in South Africa. Afr Med J 2007; 97(8): 582-3.

28. Al-Haji I, Al-Jawadi A, Al-Neema B. Mortality of under five of age in Rawthat Bany Hamdan. Expermint field services in Hamam Al- Aleel; 1992.

29. Ahmad WG. Measuring under five mortality rate in $\mathrm{m}$ during the inequitable Embargo on Iraq. Journal of education and science 2003; 15 (1): 100-105.
30. Linnan M, Anh L, Cuong V, Rahman F, Rahman A, Shumona S, Sitti-amorn C, Chaipayom O, Udomprasertgul V, LimQuizon M, Zeng G, Rui-wei J, Liping Z, Irvine $\mathrm{K}$, Dunn $\mathrm{T}$. Child mortality and injury in asia: survey results and evidence. UNICEF :Special Series on Child Injury $2007 ; 3$.

31. National Statistics Office. Infant and child deaths here are among the highest in Southeast Asia; high risk fertility behavior eyed National Demographic and Health Survey; 2003.

32. Roberts L, Lafta R, Garfield R, Khudhairi J, Burnham G. Mortality before and after the 2003 invasion of Iraq: cluster sample survey. Elsevier Ltd; 2004. http://image.thelancet.com/extras/04art103 42web.pdf 7 . 